\title{
Effectiveness of EDTA as the irrigation solution to remove smear layer in root canal
}

\author{
Kurniasri Amas Achiar, Endang Sukartini \\ Department of Conservative Dentistry Faculty of Dentistry Universitas Padjadjaran
}

\begin{abstract}
One of the objectives of successful endodontic treatment is the hermetis obturation of the root canal system. To achieve this, the root canal filling must seal the canal space both apically and coronally to prevent the ingress of microorganisms or tissue fluids into the canal space. Apical leakage is reported a common reason for the clinical failure of endodontic therapy. Leakage through an obturated root canal is expected to take place at interfaces between sealer and dentin or sealer and gutta-percha, or through voids within the sealer. Hence, the sealing quality of root canal filling depends much on the sealing ability of the sealer. Therefore, anything that may influence the adaptation of the root filling to the canal wall is can determining the degree and the extent of leakage, and ultimately the prognosis of the endodontic therapy. In endodontic therapy the smear layer formation results from root canal preparation and may influence the effective seal of the root canal system. The smear layer formation is mainly composed of inorganic components (dentin debris) and organic materials, such as pulp tissue remnant, bacteria, and bloods cells. Removal of the smear layer from the root canal walls before the obturation can reduced the leakage of root canal sealer. To remove the smear layer use $10 \mathrm{ml} \mathrm{17 \%} \mathrm{EDTA} \mathrm{followed} \mathrm{by} 10 \mathrm{ml}$ of 5.25\% $\mathrm{NaOCl}$ as irigating solution. This paper discribe about how the effectivity of EDTA as irigating solution to remove the smear layer especially in the apical root canal with many lateral canal to reduce the apical leakage.
\end{abstract}

Key words: Effectivity, smear layer, Ethylene Diamine Tetra-acetic Acid

\section{INTRODUCTION}

Root canal preparation is a stage that has a quite prominent importance for endodontic treatment success. In this stage, root canal content and soft dentin removal is performed to achieve a clean canal that is ready for hermetic filling. Root canal preparation during endodontic treatment produces dentinal debris that creates a layer on the root canal known as smear layer. Grossman ${ }^{1}$ stated that smear layer is a combination of dentinal debris, pulp tissues and microorganism. The complex composition and particle structure of the smear layer on the canal root wall makes it difficult to remove this layer.

The cleaning and forming process of the root canal may be conducted through mechanical process and irrigation. During the mechanical process of the root canal preparation, a smear layer that is attached to the root canal wall is produced. The removal of this preparation product depends on the technique and irrigation material used. 
The presence of smear layer in the canal root may obstruct the dentinal tubule pores and inhibit bacterial penetration to the dentinal tubules. However, the fact also shows that the presence of this smear layer may also prevent the adherence of root canal filler material to the root canal wall that may lead to apical leakage that will affect the success of root canal filling.

Ethylene Diamine Tetra-acetic Acid (EDTA) is known as a chelation material used as irrigation solution. This solution has the capability to remove dentinal smear layer during root canal irrigation. EDTA has the nature to dissolve smear layer produced during instrumentation process causing the exposure of dentinal tubules that leads to more effective antiseptic agent effect as well as increased filler material adhesion to the root canal wall. The problem is whether EDTA irrigation solution effective enough to remove smear layer in the lateral root canal to support the success of endodontic treatment?

\section{SMEAR LAYER FORMATION DURING ENDODONTIC TREATMENT}

Smear layer is a thin layer along the dentin or root canal wall formed after a root canal preparation. The root canal preparation will leaf an amorphous smear layer consisting of dentin and other debris with 1-2 um thick on the root canal and may penetrate the dentinal tubules up to $40 \mathrm{um}$.

\section{Smear layer composition}

The smear layer consists of organic and inorganic components. The organic components came from necrotic pulp and vital pulp tissues, protein coagulation, odontoblast process, saliva, blood cells and microorganisms. ${ }^{2}$ Meanwhile, the inorganic components are the most abundant components in the smear layer. These inorganic particle compositions are gained most from the demineralized dentinal structures.

\section{Smear layer formation process}

The smear layer formation process has a tight connection to the root canal preparation. The smear layer is formed due to friction between the canal root instruments and canal root wall during canal root preparation.

The thickness of smear layer formed on the dentinal surface depends on the type of root canal preparation instrument and irrigation material used in the preparation. The smear layer produced during root canal preparation will be more abundant and thicker if the mechanical instrument is used compared to the manual instrument. This is possible because the dentinal reduction by the mechanical instrument is bigger and more intensive compared to the manual instrument that the produced dentinal debris will have bigger size and bigger number.

\section{ROLE OF EDTA IRRIGATION SOLUTION IN REMO- VING SMEAR LAYER}

During and after root canal cleansing and forming, the root canal should be irrigated to remove pulp tissue residuals and dentinal debris accumulated in the root canal. The irrigation solution should be replaced continually to maintain the effectiveness. A high volume ultrasonic irrigation system has been developed to increase penetration action and irrigant debridement through ultrasonic activity.

For years, different irrigation solution has been proposed, i.e. hot water irrigation $\left(140^{\circ}-170^{\circ} \mathrm{F}\right)$ ejected from partitioned syringe, physiologic saline solution, $30 \%$ urea solution, urea peroxide in glycerine solution, chloramine solution, sodium hypochlorite solution with EDTA solution.

\section{Effectiveness of EDTA as the root canal irrigation solution}

EDTA was introduced into endodontic practice by Nyagaard-Ostby. EDTA has four acetic acid groups bound to ethylenediamine.

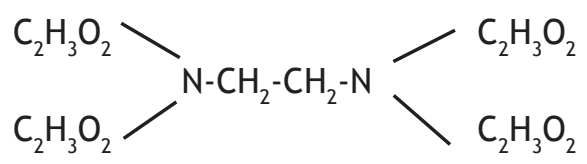

Figure 1. EDTA structure.

The effectiveness of the irrigation solution depends on:

\section{Amount of irrigation solution}

The debris removal in the root canal is comparable to the amount of the irrigation solution used. Root canal irrigation with copious irrigation 
solution will remove more debris from the root canal. The prepared root canal is irrigated with 10 $\mathrm{ml}$ of $17 \%$ EDTA followed by $10 \mathrm{ml} 5.25 \% \mathrm{NaOCl}$.

\section{Root canal diameter}

Often the root canal irrigation is a must and the irrigation will be perfect if the root canal is enlarged as appropriate. The irrigation solution will be more effective in bigger diameter root canal compared to the small apical narrowing.

\section{Pulp condition}

In pulpless tooth, irrigation solution does not only fill the whole root canal but also penetrates the periapical tissues. The irrigation solution should be replaced continuously to maintain its effectiveness. The irrigation should be performed in every stage of root canal preparation. The irrigation solution should be applied using small syringe with a pressure that is not too high because high pressure may cause the irrigation material goes in and out the periapical tissue and the patient will experience great pain.

The root canal that has been prepared is irrigated with $10 \mathrm{ml}$ of $17 \%$ EDTA solution using a syringe. It is then followed by $10 \mathrm{ml} 5.25 \%$ $\mathrm{NaOCl}$. After irrigation, the root canal is dried to neutralize EDTA action that may be active in the root canal for 5 days. According to Weine ${ }^{3}$, EDTA demineralization that is not deactivated may cause the exposure of apical constriction so that the solution will enter the periapical tissue and may destroy periapical bone.

\section{EDTA effect on root canal dentin}

The function of EDTA is to form a chelating calcium solution with dentinal calcium ion so that the dentin will be softer and easily instrumented. The concentration used in the root canal is 15\% and $17 \%$. The use of EDTA chelator with sodium hypochlorite alternately as the irrigation solution has the potential to clinically clean smear layer and organic debris. The smear layer is formed from inorganic components (dentinal debris) and organic materials such as pulp tissue, bacteria and blood cells. $\mathrm{NaOCl}$ has the ability to dissolve organic materials while EDTA dissolves inorganic materials from smear layer effectively.

\section{Removal of smear layer in lateral canal}

Grossman ${ }^{1}$ stated that irrigation solution has the ability to dissolve pulp tissue as well as having cleaning effect especially in the grooves and lateral canal that cannot be reached by mechanic preparation. The dirty root canal wall may serve as the habitat for bacteria, reduce adherence of root canal filler and increase apical leakage.

The effect of EDTA as a chemical to clean dentinal wall of the root canal has been mentioned by several authors. EDTA has a nature of dissolving the smear layer formed during root canal preparation, leading to exposed dentinal tubules so that a more effective antiseptics action can be achieved and increased adhesion of the filler to the root canal wall is attained.

The debris is not only found in the main root canal but also in the lateral and additional root canals. The presence of debris in the lateral or additional root canal will make chemical debridement and root canal filling more difficult.

The lateral root canal or accessory canals can only be detected through x-ray image after the root canal is filled. Although the lateral and accessory root canal cannot be diagnosed easily, the presence of these canals can be considered. The accessibility for antiseptics and filler depends on the elimination of debris that is produced during preparation.

As already known, sodium hypochlorite $5 \%$

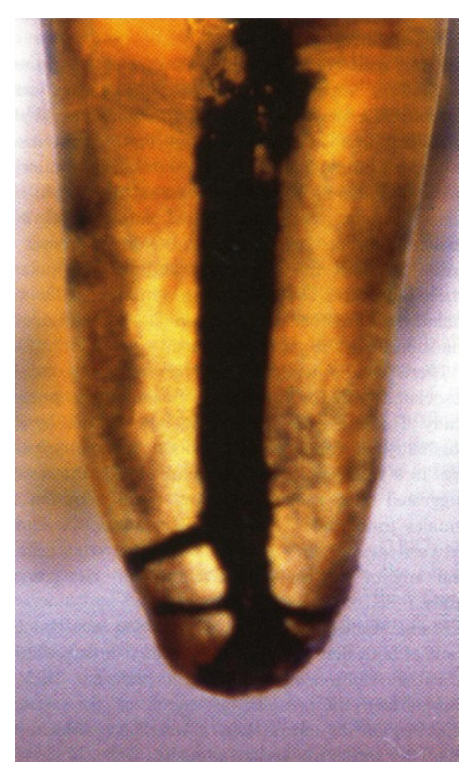

Figure 2. Lateral canal in upper first molar palatinal root. 
as the irrigation solution cannot eliminate smear layer that is produced during instrumentation. On the contrary, EDTA works as smear layer eliminating agent that produces clean root canal wall. The results from a study performed by Gelberg et al. ${ }^{4}$ indicates that root canal irrigation by using EDTA alternately with $5 \%$ sodium hypochlorite will increase the number of filled lateral and accessory root canal. It is believed that EDTA also has similar effects as irrigation solution for lateral and accessory root canal that it will contribute to the success of the endodontic treatment.

\section{The effect of smear layer in endodontic treatment}

The smear layer will influence dentin permeability and prevent bacterial colonization. Walton and Rivera ${ }^{5}$ stated that one of the benefits of the presence of smear layer on the root canal is that it can prevent bacterial colonization. Smear layer can also function as barrier for bacterial development in dentinal tubules and will "lock" the bacteria inside, preventing the bacteria to colonize. ${ }^{6}$ However, when the smear layer is removed from the root canal wall, it will enable tight attachment between root canal filler and root canal dentinal wall so that it will reduce root canal filler leakage.

\section{CONCLUSION}

Root canal irrigation using EDTA alternately with $5 \%$ sodium hypochlorite will dilute formed smear layer during root canal preparation leading to dentinal tubule exposure, production of lateral and accessory canal increasing the number of lateral and accessory canal filled to support endodontic treatment success. EDTA irrigation solution is effective enough to remove smear layer on lateral root canal to support the success of endodontic treatment.

\section{REFERENCES}

1. Grossman LI. Endodontics Practice. $11^{\text {th }}$ ed. Philadelphia: Lea Febiger; 1995.

2. Mader LC, Baumgartner JC, Peters DD. Scanning electron microscopic investigation of the smeared layer on the root canal walls. J Endod 1984:477-83.

3. Weine FS. Endodontic therapy. $5^{\text {th }}$ ed. Philadelphia: Mosby; 1996. p. 127-9.

4. Gelberg F, Massone JE, Spielberg C. Endodontics. Dent J Traumatology 1986;2:656.

5. Walton RE, Rivera EM. Cleaning and shaping In: Principles and practice of endodontics. $3^{\text {rd }}$ ed. Philadelphia: W.B.Saunders Co.; 2002.

6. Bergenholtz G. Textbook of endodontology. Victoria: Blackwell Munksgaard; 2003. 